\title{
Household dietary diversity and associated factors among residents of finote selam town, north west Ethiopia: a cross sectional study
}

\author{
${\text { Getnet Mekuria }{ }^{1 *}, \text { Yalewsew Wubneh}^{2} \text { and Tilahun Tewabe }}^{3}$
}

\begin{abstract}
Background: Monotonous low quality diets are the norm in resource-limited environments across the globe. Dietary diversity is a challenge for rural communities in developing countries. Their diets are based on starchy staples with inadequate animal products, fresh fruits and vegetables.

Methods: A community based cross sectional study was conducted from August 22-30, 2015 at Finote Selam Town. Systematic random sampling technique was used to select 400 households. Data were collected using pretested and semi-structured questionnaire. Both bivariate and multivariate logistic regression analyses were carried out to identify factors associated with household dietary diversity.

Results: The prevalence of low, medium and high dietary diversity scores were 11.8, 67.2 and 21\% respectively. Family head (Men headed) $[A O R=4.75(2.22,10.16)]$, frequency of eating $[A O R=6.06(2.82,13.06)]$ and shortage of water for cooking $[A O R=5.69(1.39,23.27)]$ were significantly associated with household dietary diversity.

Conclusions: In this study the prevalence of adequate household diversity was $88.2 \%$. Family head, frequency of eating and shortage of water for cooking were significant factors for household dietary diversity. Empowering women, increasing frequency of eating among family members and avoiding shortage of water for cooking were recommended to sustain and improve household dietary diversity.
\end{abstract}

Keywords: Household dietary diversity, Finote Selam Town

\section{Background}

Monotonous low quality diets are the norm in resourcelimited environments across the globe. Risks for a range of micronutrient deficiencies are high when grain or tuber-based staple foods dominate and diets lack vegetables, fruits and animal-source foods. Dietary diversity is widely recognized as a key dimension of diet quality. Evidences from developed countries showed that dietary diversity is strongly associated with nutrient adequacy [1].

Dietary diversity which is defined as an increase in the variety of foods within and across food groups capable of ensuring adequate intake of essential nutrients that

\footnotetext{
* Correspondence: getnetmekuria70@yahoo.com

${ }^{1}$ Department of Applied Human Nutrition, Bahir Dar Institute of Technology, Bahir Dar University, Bahir Dar, Ethiopia

Full list of author information is available at the end of the article
}

can promote good health, physical as well as mental development [2]. The more food groups included in daily diet the greater the likelihood of meeting nutrient requirements because all nutrients can't be found within a single food item [3].

In developing countries, dietary diversity is a challenge for rural communities. Their diets are based on starchy staples with inadequate animal products, fresh fruits and vegetables. In countries where resources are limited, lack of access to adequate and diversified diet has been identified as one of the severe problems among poor populations that resulted various forms of nutritional problems [4]. Chronic energy deficiency, inadequate energy intake and micronutrient deficiencies are among the top priority nutritional problems that affect women of reproductive age [5]. 
In areas where household food security is poor, meeting minimum standards of dietary quality is another challenge in many developing country settings and it has often not given enough emphasis [6]. Now, developing countries are burdened with the 'triple burden of malnutrition' encompasses the three dimensions of under nutrition (wasting, stunting \& underweight), micronutrient deficiencies and over nutrition. Food security policies should focus not only on calorie intake but also consumption of a diversified diet. Consumption of a diversified diet promotes the intake of different nutrients and thus prevents many diseases. Reduction in dietary diversity will lead to an increase in the proportion of malnourished people [7].

Ethiopia Socioeconomic Survey (ESS) - 2013/14 reported that cereals (rice, sorghum, barley, wheat) are the most consumed food items with $90 \%$ of all households reporting consumption of at least one of these items in any form in six of the last 7 days on average [8]. In Ethiopia, 60 and $40 \%$ of households had low and medium diet diversity scores [9]. A non-diversified diet can have negative consequences on individuals' health, well-being and development, mainly by reducing physical capacities as well as resistance to infection. In addition, cognitive development, reproductive and even social capacities may also be impaired [10]. Therefore, the aim of this study was to assess household dietary diversity and associated factors among residents of Finote Selam Town.

\section{Methods}

\section{Study setting and participants}

A community based cross sectional study was conducted from August 22-30/2015 in Finote Selam Town which is located at a distance of $380 \mathrm{Km}$ North-West of Addis Ababa. The town has approximately 39585 total population and 5248 households. The study populations were permanent residents of Finote Selam Town from August 22-30/2015.

The sample size was calculated by using a single population proportion formula with the following considerations; prevalence of consuming diversified diet (60.4\%) from previous research conducted in Addis Ababa [11], 95\% confidence level, $5 \%$ margin of error and a $5 \%$ non response rate. A total of 403 households were selected using a systematic random sampling technique from a list of all households of the town.

\section{Measurements}

Interviewer administered questionnaire was used to collect data from respondents. First, the English version of the questionnaire was prepared, translated to Amharic and then back to English by language translators in order to check for consistency.
The respondents were asked to recall all foods eaten and beverages taken in the previous twenty-four hours prior to the interview. A scale of twelve food groups was used in assessing the dietary diversity of the respondents. A single point was given to each of the food groups consumed over the reference period giving a maximum sum total dietary diversity score of 12 points for each household.

For data collection eight diploma nurses and for supervision two Bachelor of Science nurses were recruited and trained for one day before data collection started.

\section{Operational definitions}

Household: One or more people who live in the same dwelling and also share at meals or living accommodation, and may consist of a single family or some other grouping of people.

Household dietary diversity: Refers to the number of food groups consumed by household members over a 24-hour period.

Low household dietary diversity score: When households consumed less than or equal to three food groups within 24 h before the survey [6].

Medium household dietary diversity score: When households consumed four to six food groups within $24 \mathrm{~h}$ before the survey [6].

High household dietary diversity score: When households consumed seven or more food groups within $24 \mathrm{~h}$ before the survey [6]

Adequate household dietary diversity: When households consumed at least four or above food groups within $24 \mathrm{~h}$ before the survey.

Inadequate household dietary diversity: When households consumed less than four food groups within $24 \mathrm{~h}$ before the survey.

\section{Data processing and analysis}

Data were checked for completeness and entered (double entry) into Epi data version 3.1. Data were cleaned and coded using Epi data and transferred to SPSS version 20 for analysis. Descriptive statistics were used to characterize respondents using different variables of interest. First, bivariate logistic regression analysis was undertaken for each explanatory variable with the outcome variable (household dietary diversity). Variables with a p-value $\leq 0.2$ on bivariate logistic regression analysis were included in the multivariate logistic regression analysis. Statistical significance was determined using odds ratio with a 95\% confidence interval. Statistical significance was declared if $\mathrm{p}$-value was $<0.05$.

\section{Ethical consideration}

Ethical clearance was obtained from Debre Markos University College of medicine and Health Sciences 
ethical review committee and permission also obtained from Finote Selam district health office as well as each kebele administration units. Informed verbal consent was obtained from the study participants and the objective of the study was explained to them. Those who were not volunter to participate are not enforced to respond.

Table 1 Socio-demographic characteristics of respondents: West Gojjam Zone North west Ethiopia Finote Selam town November, 2015. $(n=400)$

\begin{tabular}{lll}
\hline Variables & Frequency & Percent \\
\hline Age (in year) & & \\
$18-45$ & 293 & 73.2 \\
$46-60$ & 72 & 18.0 \\
$>60$ & 35 & 8.8
\end{tabular}

Religion

$\begin{array}{lll}\text { Orthodox } & 372 & 93.0 \\ \text { Muslim } & 20 & 5.0 \\ \text { Protestant } & 8 & 2.0\end{array}$

Residence

Urban

Rural

Family head

Women headed

Men headed

Marital status of respondent

Single

Married

Divorced

Widowed

Family size

$1-2$

3-4

Greater than 4

Educational status of head of the family

Unable to read and write

Read and write only

1-8 grade

9-12 grade

Diploma and above

Occupation of head of the family

$\begin{array}{ll}\text { Government employed } & 63 \\ \text { Private employed } & 23 \\ \text { Daily laborer } & 66 \\ \text { Farmer } & 99 \\ \text { Merchant } & 149\end{array}$

Diploma = someone who successfully completed a three year course of study from College
Confidentiality and privacy of collected information ensured at all levels.

\section{Results}

Socio-demographic characteristics of households

Of the 403 eligible respondents, 400 agreed to participate in this study, which made a response rate of $99.3 \%$. The mean age of the respondents was 39.87 years (standard deviation, SD \pm 10.95$)$. Among respondents 293 (73.2\%), $72(18 \%)$ and $35(8.8 \%)$ were $19-45,46-60$ and above 60 years age group respectively (Table 1 ).

\section{Socio-economic and dietary characteristics}

Two hundred fifty three (63.2\%) of households were food secured. Cereals (88.6\%), vegetables $43(10.7 \%)$ and animal products $3(0.7 \%)$ were commonly consumed foods (Table 2 and 3 ).

Almost all (99\%) of respondents consumed cereal food groups and half $(50.5 \%)$ of them also consumed vegetables (Table 4).

\section{Factors associated with household dietary diversity}

Hosmer-Lemeshow goodness-of-fit test $(\underline{p}=0.144)$ was used to assess the fitness of the model. During the bivariate logistic regression analysis; head of the family, frequency of eating per $24 \mathrm{~h}$, water shortage for cooking, ownership of farming land and household food insecurity access score were significantly associated with household dietary diversity.

During the multivariate logistic regression analysis; head of the family, frequency of eating per $24 \mathrm{~h}$ and water shortage for cooking were significantly associated with household dietary diversity. But, ownership of farming land and household food insecurity access score

Table 2 Socio-economic characteristic of Finote Selam town residents; 2015

\begin{tabular}{lll}
\hline Variables & Frequency & Percent \\
\hline Grow vegetables & 107 & 26.7 \\
Yes & 293 & 73.3 \\
No & & \\
Farming land & 129 & 32.2 \\
$\quad$ Yes & 271 & 67.8 \\
No & & \\
Irrigation scheme users & 33 & 8.2 \\
Yes & 367 & 91.8 \\
No & & \\
Monthly income & \\
$\quad \leq 500$ birr & 88 & 22 \\
$501-1000$ birr & 106 & 26.5 \\
$>1000$ birr & 206 & 51.5 \\
\hline 1 Ethiopian birr =0.05 USD & &
\end{tabular}

${ }^{\mathrm{a}} 1$ Ethiopian birr $=0.05$ USD 
Table 3 Dietary characteristics of Finote Selam town residents; 2015

\begin{tabular}{|c|c|c|}
\hline Variables & Frequency & Percent \\
\hline \multicolumn{3}{|l|}{ Dietary diversity } \\
\hline Non-diversified & 47 & 11.8 \\
\hline Diversified & 353 & 88.2 \\
\hline Low & 47 & 11.8 \\
\hline Medium & 269 & 67.2 \\
\hline High & 84 & 21 \\
\hline \multicolumn{3}{|l|}{ Breakfast eaten } \\
\hline Yes & 382 & 95.5 \\
\hline No & 18 & 4.5 \\
\hline \multicolumn{3}{|l|}{ Water shortage for cooking } \\
\hline Yes & 10 & 2.5 \\
\hline No & 390 & 97.5 \\
\hline \multicolumn{3}{|l|}{ Food insecurity access score } \\
\hline Food secure & 253 & 63.2 \\
\hline Mildly food insecure & 76 & 19 \\
\hline Moderately food insecure & 56 & 14 \\
\hline Severe food insecure & 15 & 3.8 \\
\hline \multicolumn{3}{|l|}{ Who got health education } \\
\hline Yes & 7 & 1.8 \\
\hline No & 393 & 98.2 \\
\hline \multicolumn{3}{|l|}{ Commonly eaten foods } \\
\hline Cereals & 354 & 88.5 \\
\hline Vegetables & 43 & 10.8 \\
\hline Animal products & 3 & 0.8 \\
\hline \multicolumn{3}{|l|}{ Frequency of eating } \\
\hline Two times & 24 & 6 \\
\hline Three times & 311 & 77.8 \\
\hline Four times and above & 65 & 16.2 \\
\hline
\end{tabular}

were not associated with household dietary diversity. The odds of household dietary diversity is higher among men headed families $[\mathrm{AOR}=4.75(2.22,10.16)]$, frequency of eating three times and above per $24 \mathrm{~h}$ [AOR = $6.06(2.82,13.06)]$ and no shortage of water for cooking [AOR $=5.69(1.39,23.27)]$ (Table 5).

\section{Discussion}

This community based cross- sectional study assessed household dietary diversity and associated factors in Amhara region, West Gojjam zone, Finote Selam town in 2015. The major goal of dietary diversity is to promote households to consume diversified diets rather than consuming monotonous diets throughout $24 \mathrm{~h}$.

The results of this study showed that low, medium and high household dietary diversity scores in Finote Selam town were found to be $11.8,67.2$ and $21 \%$ respectively.
Table 4 Household dietary score of Finote Selam town; 2015

\begin{tabular}{|c|c|c|c|}
\hline & Consumption of & Frequency(yes) & Percentage \\
\hline 1 & $\begin{array}{l}\text { ANY LOCAL FOODS, bread, rice } \\
\text { noodles, biscuits, or any other } \\
\text { foods made from millet, sorghum, } \\
\text { maize, rice, wheat, or any other } \\
\text { locally available grain? }\end{array}$ & 398 & 99 \\
\hline 2 & $\begin{array}{l}\text { Any potatoes, yams, manioc, cassava } \\
\text { or any other foods made from roots } \\
\text { or tubers? }\end{array}$ & 48 & 12 \\
\hline 3 & Any vegetables? & 203 & 50.75 \\
\hline 4 & Any fruits? & 30 & 7.5 \\
\hline 5 & $\begin{array}{l}\text { Any beef, pork, lamb, goat, rabbit wild } \\
\text { game, chicken, duck, or other birds, } \\
\text { liver, kidney, heart, or other organ } \\
\text { meats? }\end{array}$ & 79 & 19.7 \\
\hline 6 & Any eggs? & 32 & 8 \\
\hline 7 & Any fresh or dried fish or shellfish? & 1 & 0.2 \\
\hline 8 & $\begin{array}{l}\text { Any foods made from beans, peas, } \\
\text { lentils, or nuts? }\end{array}$ & 312 & 77.6 \\
\hline 9 & $\begin{array}{l}\text { Any cheese, yogurt, milk or other milk } \\
\text { products? }\end{array}$ & 42 & 10.4 \\
\hline 10 & $\begin{array}{l}\text { Any foods made with oil, fat, or } \\
\text { butter? }\end{array}$ & 300 & 74.6 \\
\hline 11 & Any sugar or honey? & 156 & 38.8 \\
\hline 12 & $\begin{array}{l}\text { Any other foods, such as condiments, } \\
\text { coffee, tea? }\end{array}$ & 360 & 89.6 \\
\hline
\end{tabular}

Table 5 Factors associated with household dietary diversity of Finote Selam Town residents; 2015

\begin{tabular}{|c|c|c|c|c|}
\hline \multirow[t]{2}{*}{ Variables } & \multicolumn{2}{|c|}{ Dietary diversity } & \multirow[t]{2}{*}{ COR 95\% Cl } & \multirow[t]{2}{*}{ AOR 95\% Cl } \\
\hline & Diversified & Non-diversified & & \\
\hline \multicolumn{5}{|c|}{ Head of the family } \\
\hline $\begin{array}{l}\text { Women } \\
\text { headed }\end{array}$ & 127(31.8) & $36(9.0)$ & 1.00 & 1.00 \\
\hline $\begin{array}{l}\text { Men } \\
\text { headed }\end{array}$ & $226(56.5)$ & $11(2.8)$ & $5.82(2.87,11.84)$ & $4.75(2.22,10.16)$ \\
\hline \multicolumn{5}{|c|}{ Frequency of eating } \\
\hline 2 times & $27(6.8)$ & $18(4.5)$ & 1.00 & 1.00 \\
\hline $\begin{array}{l}3 \text { times and } \\
\text { above }\end{array}$ & $326(81.5)$ & $29(7.2)$ & $7.49(3.69,15.19)$ & $6.06(2.82,13.06)$ \\
\hline \multicolumn{5}{|l|}{ Water shortage } \\
\hline Yes & $5(1.2)$ & $5(1.2)$ & 1.00 & 1.00 \\
\hline No & $348(87.0)$ & $42(10.5)$ & $8.29(2.30,29.81)$ & $5.69(1.39,23.27)$ \\
\hline \multicolumn{5}{|c|}{ Ownership of farming land } \\
\hline Yes & 123(30.8) & $6(1.5)$ & $3.65(1.51,8.85)$ & \\
\hline No & $230(57.5)$ & $41(10.2)$ & 1.00 & \\
\hline \multicolumn{5}{|l|}{ HHFIAS } \\
\hline $\begin{array}{l}\text { Food } \\
\text { secured }\end{array}$ & $236(59.0)$ & $17(4.2)$ & $3.56(1.89,6.72)$ & \\
\hline $\begin{array}{l}\text { Food } \\
\text { insecure }\end{array}$ & $117(29.2)$ & $30(7.5)$ & 1.00 & \\
\hline
\end{tabular}


Previous study (Zinet NH, 2013) conducted in Addis Ababa Ethiopia reported that 5.960 .4 and $33.7 \%$ of the households had low, medium and high Dietary Diversity Scores (DDS) respectively [11]. Belachew T and Yemane T [12] reported that $39.7 \%$ of people 40 years and above in Jimma town, Southwest Ethiopia had non-diversified diet. Misker D., Misker B and Ayele G [13] revealed that 65.7 and $34.3 \%$ of the households had low and high dietary diversity scores. Taruvinga A, Muchenje V and Mushunje A [14] revealed that 29.3, 35.9 and $34.8 \%$ of rural households had low, medium and high dietary diversity scores. Rasaki SA [15] reported that 16.5 and $83 \%$ of the respondents had low and average/medium DDS. Sarkar S [16] reported that 39,40 and $21 \%$ of the households have low, medium and high dietary diversity scores respectively. These differences might be due to variations in socio-economic status, agro-ecology, culture, time etc. In addition, the higher prevalence of adequate household dietary diversity in the study area is due to the presence of religious festival among orthodox Christian community during data collection period.

Head of the family is among various socio-demographic factors that shows significant association with household dietary diversity in this study. The odds of having adequate household dietary diversity is 4.75 times higher among men headed families compared to women headed. This has similarities with study findings from Amatole and Nyandeni districts, South Africa [14], Mirab Abaya wereda, Southern Ethiopia [13], rural households in West Bengal, India [16], Sri Lanka [17] and Ethiopia [18]. This could be due to male headed households have more money at their disposal hence the higher dietary diversity.

Frequency of eating per $24 \mathrm{~h}$ is another dietary factor that has a significant association with household dietary diversity. The odds of having adequate household dietary diversity is 6.06 times higher among households who consumed food three times \& above compared to households who consumed food two times. This could be explained by the fact that increasing frequency of consuming food items is one of the strategies to increase dietary diversity of households.

Availability of water for cooking is one of the prerequisites for ensuring adequate household dietary diversity. No shortage of water for cooking is significantly associated with household dietary diversity in this study. The odds of having adequate household dietary diversity is 5.69 times higher among households who didn't have water shortage for cooking compared to households who had water shortage. This could be due to the fact that clean water is important for washing, preparing and cooking our food items.

The limitations of this study are relying on $24 \mathrm{~h}$ dietary recall which doesn't show the usual dietary practice of household members and affected by religious festivals.

\section{Conclusions}

In this study the magnitude of adequate household diversity was $88.2 \%$. Family head, frequency of eating and shortage of water for cooking were significant factors for household dietary diversity. Empowerment of women, increasing frequency of eating among family members and avoiding shortage of water for cooking were recommended to sustain and improve household dietary diversity.

\section{Abbreviations}

AOR: Adjusted odds ratio; Cl: Confidence interval; COR: Crude odds ratio; DDS: Dietary diversity scores; FAO: Food and Agriculture Organization of the United Nations; HHFIAS: Household food insecurity access score; KM: Kilo meter; SD: Standard deviation; SPSS: Statistical package for social sciences; USD: United States of America Dollar

\section{Acknowledgements}

We would like to thank Finote Selam town administration health office for their support to conduct the study and for providing all the required information. We would also thank all respondents for their genuine response during the interviews and the data collectors as well as supervisors for their kind cooperation, strong commitment and honesty.

\section{Funding}

There is no organization that funds this research.

Availability of data and materials

The datasets used and/or analyzed during the current study available from the corresponding author on reasonable request.

\section{Authors' contributions}

YW conceived and designed the study, performed the analysis and interpretation of data. GM and TT assisted with the design, conception, analysis and interpretation of data. GM also write-up and drafted the manuscript. All authors read and approved the final manuscript.

\section{Competing interests}

The authors declare that no competing interests.

\section{Consent for publication}

Consent for publication is not necessary because this manuscript didn't have personal data like individual details, images or videos.

Ethics approval and consent to participate

Ethical clearance was obtained from Debre Markos University College of medicine and Health Sciences ethical review committee and permission also obtained from Finote Selam town administration health office well as each kebele administration units. Informed verbal consent was obtained from the study participants and the objective of the study was explained to them. Those who were not volunter to participate were not enforced to respond. Privacy and confidentiality of collected information ensured at all levels.

\section{Publisher's Note}

Springer Nature remains neutral with regard to jurisdictional claims in published maps and institutional affiliations.

\section{Author details}

1 Department of Applied Human Nutrition, Bahir Dar Institute of Technology, Bahir Dar University, Bahir Dar, Ethiopia. 'World Vision Ethiopia, Finote Selam, Ethiopia. ${ }^{3}$ Department of Nursing, College of Medicine and Health Sciences, Bahir Dar University, Bahir Dar, Ethiopia. 
Received: 9 December 2016 Accepted: 10 March 2017

Published online: 21 March 2017

\section{References}

1. Daniels CM. Dietary diversity as a measure of Women's diet quality in resource-poor areas: results from metropolitan Cebu, Philippines site. Washington: Food and Nutrition Technical Assistance II Project (FANTA-2); 2009.

2. Arimond M, Ruel MT. Summary indicators for infant and child feeding practices: an example from the Ethiopia demographic and health survey 2000, Food consumption and nutrition division discussion paper. Washington: International Food Policy Research Institute; 2002.

3. Labadarios D, Steyn NP, J Nel. How diverse is the diet of adult South African? Nutr J. 2011;10(33).

4. Ekesa B, Blomme G, Garming H. Dietary diversity and nutritional status of preschool children from musa- dependent households in Gitega(Burundi) and Butembo(Democratic Republic of Congo). Afri J Food Agric Nutr Dev. 2011;11(4)

5. Marita L. Dietary diversity and nutritional status of pregnant women aged 15-49 years attending Kapenguria district hospital west pokot country, Kenya. 2013;10-15. http://ir-library.ku.ac.ke/handle/123456789/7486.

6. FAO. Guidelines for measuring household and individual dietary diversity. Rome: Food and Agriculture Organization of the United Nations; 2011.

7. Torlesse H, Kiess L, Bloem MW. Association of household rice expenditure with child nutritional status indicates a role for macroeconomic food policy in combating malnutrition. J Nutr. 2003;133:1320-5.

8. Central Statistical Agency \& Living Standards Measurement Study (LSMS), World Bank. Ethiopia Socioeconomic Survey Report. Central Statistical Agency \& World Bank; 2015.

9. Degye G, Belay K, Mengistu K. Measuring diet quantity and quality dimensions of food security in rural Ethiopia. J Dev Agric Econ. 2013;5(5): 174-85.

10. Savy M, Martin-prevel Y, Sawadogo P, Kameli Y, Delpeuch F. Use of variety/ diversity scores for diet quality measurement: relation with nutritional status of women in a rural area in Burkina Faso. Eur J Clin Nutr. 2005;59:703-16.

11. Zinet NH. Determinants of household dietary diversity and nutritional status of women in reproductive age group: The case of Addis Ababa. 2013:1-2. Available at http://erepository.uonbi.ac.ke:8080/xmlui/handle/123456789/ 44200, Date: 2013

12. Belachew T, Yemane T. Dietary diversity among people 40 years and above in Jimma town Southwest Ethiopia. Ethiop J Health Sci. 2007; 17(3).

13. Misker D, Misker B, Ayele G. House hold dietary diversity and associated factors in Mirab Abaya wereda Southern Ethiopia; community based cross sectional study. Divers Equal Health Care. 2016;13(4):293-6.

14. Taruvinga A, Muchenje $V$, Mushunje A. Determinants of rural household dietary diversity: The case of Amatole and Nyandeni districts, South Africa. Int J Dev Sustain. 2013;2(4).

15. Rasaki SA. An assessment of dietary diversity in Six Nigerian states. Afr J Biomed Res. 2010;13:161-7.

16. Sarkar S. Households' Dietary Diversity: A Study of Rural Households in West Bengal, India. Eur Acad Res. 2014;2(6).

17. Jayawardena R, Byrne NM, Soares JM, Katulanda P, Yadav B, Hills PA. High dietary diversity is associated with obesity in Sri Lankan adults: an evaluation of three dietary scores. BMC Public Health. 2013;13:314

18. Workicho A, Belachew T, Tolu GF, Wondafrash B, Carl L, Roosmarijn V, Patrick K. Household dietary diversity and animal source food consumption in Ethiopia: evidence from the 2011 welfare monitoring survey. BMC Public Health. 2016;16:1192

\section{Submit your next manuscript to BioMed Central and we will help you at every step:}

- We accept pre-submission inquiries

- Our selector tool helps you to find the most relevant journal

- We provide round the clock customer support

- Convenient online submission

- Thorough peer review

- Inclusion in PubMed and all major indexing services

- Maximum visibility for your research

Submit your manuscript at www.biomedcentral.com/submit
) Biomed Central 